\title{
Enfrentamento da vulnerabilidade no consumo de álcool entre universitários: ponderações de acadêmicos do PET-Saúde
}

\author{
Facing the vulnerability in alcohol consumption among undergraduate: \\ considerations of PET-Saúde students
}

\section{Afrontamiento a la vulnerabilidad en el consumo de alcohol entre universitarios: ponderaciones de academicos del PET-salud}

\author{
LUCIMARE FERRAZ* \\ FATIMA FERRETTI** \\ ALINE TECCHIO BORSOI*** \\ VANISE DAL PIVA**** \\ VIVIAN BREGLIA ROSA VIEIRA*****
}

\begin{abstract}
RESUMO
Este artigo relata uma vivência de educação em saúde que teve por objetivo trabalhar, de maneira inovadora, o tema consumo de bebidas alcoólicas entre universitários, com atores do Programa de Educação pelo Trabalho para a Saúde (PET-Saúde), de uma universidade do oeste de Santa Catarina. Para fundamentar a intervenção, inicialmente realizouse uma revisão integrativa da literatura para identificar a prevalência do consumo de álcool entre universitários brasileiros. Na sequência, utilizou-se a estratégia da construção de painel com as opiniões dos sujeitos sobre a temática. A intervenção permitiu aos estudantes do PET-Saúde a aproximação com o contexto atual sobre o consumo de álcool entre universitários, resultando em propostas de enfrentamento dessa vulnerabilidade. Concluiu-se que essa foi uma experiência exitosa de formação em saúde, pois os petianos constituíram-se em agentes multiplicadores de conhecimentos entre seus pares na universidade.
\end{abstract}

Palavras-chave: Consumo de bebidas alcoólicas. Estudantes. Educação superior.

\begin{abstract}
This paper reports an experience of health education that aimed to work in an innovative way, with actors of the Program for Education through Work for Health (PET-Saúde), of a university in western Santa Catarina, the issue of alcohol drinking among undergraduates. To support the intervention an integrative literature review was initially held, in order to identify the prevalence of alcohol consumption among Brazilian university students. Further, it was used the strategy of building a panel with the subjects' opinions about the theme. The intervention allowed the PET-Saúde students an approach to the current context on alcohol consumption among undergraduates, resulting in proposals for dealing with this vulnerability. It was concluded that this was a successful training experience in health, because PET-Saúde students constituted themselves as multipliers of knowledge among peers at university.
\end{abstract}

Keywords: Alcohol drinking. Students. Higher education.

\section{RESUMEN}

Este artículo relata una vivencia de educación en la salud que tuvo por objetivo trabajar, de manera inovadora, el tema consumo de alcohol entre los estudiantes universitarios, con los actores del Programa de Educación para la Salud para trabajar (PET-Salud), una Universidad del Oeste de Santa Catarina. Para apoyar la intervención, inicialmente

\footnotetext{
* Doutora em Ciências da Saúde, docente do Programa de Pós Graduação Stricto Sensu em Ciências da Saúde da Universidade Comunitária da Região de Chapecó - UNOCHAPECÓ.E-mail: <lferraz@unochapeco.edu.br>.

** Doutora em Ciências da Saúde, docente do Programa de Pós Graduação Stricto Sensu em Ciências da Saúde da Universidade Comunitária da Região de Chapecó - UNOCHAPECÓ.E-mail: <ferrettifisio@yahoo.com.br>.

*** Mestre em Ciências da Saúde pela Universidade Comunitária da Região de Chapecó - UNOCHAPECÓ.E-mail: <aline.borsoi@gmail.com>.

**** Mestre em Ciências da Saúde pela Universidade Comunitária da Região de Chapecó - UNOCHAPECÓ.E-mail: <nisedal@unochapeco.edu.br>.

***** Mestre em Ciências da Saúde pela Universidade Comunitária da Região de Chapecó - UNOCHAPECÓ. E-mail: <vivian.vieira@unochapeco.edu.br>.
} 
celebrado una revisión integradora de la literatura para identificar la prevalencia de consumo de alcohol entre la universidad brasileño. Siguiendo, se utilizó la construcción del panel de la estrategia con las opiniones de los sujetos sobre el tema. La intervención permitió a los estudiantes enfoque PET-Salud al contexto actual de consumo de alcohol entre los estudiantes universitarios, lo que resulta en propuestas para hacer frente a esta vulnerabilidad. Se concluyó que se trataba de una experiencia exitosa de educación para la salud, como petianos formado en multiplicadores del conocimiento entre sus compañeros de la universidad.

Palabras clave: El consumo de bebidas alcohólicas. Estudiantes. Educación universitaria.

\section{INTRODUÇÃO}

O consumo de bebida alcoólica é a causa atribuída a mais de 60 tipos de enfermidades. Porém, os efeitos do consumo excessivo de álcool vão além das consequências à saúde, gerando um conjunto de custos sociais associados a violência interpessoal, homicídios, comportamento sexual de risco, aumento da incidência de doenças infectocontagiosas e acidentes de trânsito (BRASIL, 2010).

Entre os usuários, os jovens constituem um grupo vulnerável ao consumo de bebidas alcoólicas. Barbosa et al. (2013) advertem que esse consumo exagerado entre jovens é um fator preocupante, não somente pelos danos pessoais que causa, mas também pelo impacto no desenvolvimento de habilidades cognitivocomportamentais, além da violência e dos prejuízos ao patrimônio público.

Observa-se que os universitários são indivíduos com grande vulnerabilidade ao consumo de bebidas alcoólicas por apresentarem um estilo de vida diferente dos jovens não universitários (BRASIL, 2014). A entrada na universidade se constitui em uma fase de mudanças na vida dos jovens. Novas relações sociais e adoção de comportamentos diferentes são comuns, e, para muitos, essas mudanças se configuram como um momento de maior vulnerabilidade, tornando-os mais susceptíveis ao uso de drogas ou álcool (VIEIRA et al., 2002). Um levantamento nacional sobre o uso de álcool, tabaco e outras drogas entre universitários das 27 capitais brasileiras revelou que o consumo de álcool foi relatado por $74,6 \%$ dos universitários entrevistados em todo o Brasil (BRASIL, 2010).

Considerando os apontamentos de que o grupo de universitários é vulnerável ao consumo de álcool, torna-se relevante promover práticas de educação em saúde para fomentar o debate em torno do tema, visando a motivar os universitários a refletir sobre estratégias de intervenção que promovam o enfrentamento dessa problemática.

Diante desse contexto, os temas álcool, universidade e universitários foram trabalhados junto dos atores do Programa de Educação pelo Trabalho para a Saúde (PET-Saúde), já que o PET-Saúde tem por são objetivos: I) possibilitar a formação dos profissionais da saúde, de acordo com características sociais e regionais; II) estimular a formação de profissionais e docentes de elevada qualificação técnica, científica, tecnológica e acadêmica, pautada pelo espírito crítico, pela cidadania e pela função social da educação superior, orientados pelo princípio da indissociabilidade entre ensino, pesquisa e extensão, preconizado pelo Ministério da Educação; III) desenvolver atividades acadêmicas em padrões de qualidade de excelência, mediante grupos de aprendizagem tutorial de natureza coletiva e interdisciplinar; IV) contribuir para a implementação das Diretrizes Curriculares Nacionais dos cursos de graduação da área da saúde; V) contribuir para a formação de profissionais de saúde com perfil adequado às necessidades e às políticas de saúde do país; VI) sensibilizar e preparar profissionais da área para o adequado enfrentamento das diferentes realidades de vida e de saúde da população brasileira; VII) induzir o provimento e favorecer a fixação de profissionais capazes de promover a qualificação da atenção à saúde em todo o território nacional; e VIII) fomentar a articulação entre ensino e serviço na área da saúde (FERRAZ, 2012).

Segundo Sordi e colaboradores, dados sobre o PETSáude demonstram repercussões positivas desse programa na relação entre instituições de ensino superior e serviços de saúde, com avanços no envolvimento de instituições e estudantes nas redes de atenção à saúde, o que fortalece o compromisso com o Sistema Único de Saúde (SORDI et al., 2015). No que se refere aos processos de formação na área da saúde, é perceptível que o PET-Saúde favorece a introdução de metodologias ativas de ensinoaprendizagem, bem como proporciona a diversificação dos cenários de práticas para o ensino superior (CRUZ et al., 2015). Os projetos do PET-Saúde articulam ações de ensino-pesquisa-extensão em grupos interdisciplinares e vislumbram, por meio dessa integração, qualificar o cuidado e aprimorar a educação em saúde, especialmente, às populações vulneráveis.

Este artigo tem por objetivo socializar uma vivência exitosa de educação em saúde que estimulou atores do PET-Saúde, de uma universidade do oeste de Santa Catarina, a refletir sobre o consumo de álcool entre universitários e propor medidas para minimizar essa vulnerabilidade. 


\section{DeSENVOLVIMENTO}

Para o desenvolvimento da intervenção entre os atores do PET-Saúde, percebeu-se a necessidade de maior apropriação sobre o tema. Portanto, realizou-se uma revisão integrativa de literatura, que é relatada a seguir.

\section{Revisão integrativa}

A revisão integrativa de Literatura foi realizada com etapas conduzidas de acordo com os critérios de Ganong (1987): escolha da pergunta de pesquisa; definição dos critérios de inclusão e exclusão dos estudos; seleção da amostra; organização dos estudos selecionados; análise e discussão dos resultados. Teve como objetivo responder ao seguinte questionamento: "Como o padrão de consumo do álcool entre os estudantes universitários tem sido apresentado nas publicações de periódicos científicos brasileiros?".

Com base nos Descritores em Ciências da Saúde (Decs) e a partir do uso de termos, realizou-se a estratégia de busca. Os descritores e termos foram cruzados, em língua portuguesa, na base de dados da Biblioteca Virtual em Saúde (BVS), através de busca avançada. Optou-se pelo uso, como descritor, da palavra estudantes e, como termos, álcool, universidade, universitário, universitários, acadêmico, acadêmicos e estudante. Utilizaram-se os seguintes cruzamentos: Álcool AND Universidade; Álcool AND Universitário; Álcool AND Universitários; Álcool AND Acadêmico; Álcool AND Acadêmicos; Álcool AND Estudante; e Álcool AND Estudantes. Foram encontrados 27 artigos e selecionados, de acordo com os critérios de inclusão e exclusão do estudo, 13 estudos. Os critérios de inclusão abarcavam: trabalhos produzidos no formato de artigo científico, publicados no período de janeiro de 2006 a abril de 2014, escritos nos idiomas português, inglês e/ou espanhol, e que se referiam explicitamente ao objeto de estudo. Foram excluídos do estudo os artigos em duplicidade e os que não respondiam ao questionamento da investigação. A seguir, apresenta-se a síntese dos resultados dessa revisão integrativa.

\subsection{Resultados da revisão integrativa}

Petroianu et al. (2010), em estudo com acadêmicos de todos os anos do curso de Medicina, identificaram que $85 \%$ dos estudantes consomem álcool. Wagner e Andrade (2008), através de um levantamento bibliográfico, em publicações realizadas entre os anos de 1997 e 2007, constataram que $82,3 \%$ dos estudantes universitários consumiram álcool nos 12 meses anteriores às pesquisas realizadas.

Pedrosa et al. (2011), em pesquisa com estudantes da área da saúde de duas universidades públicas de Maceió, verificaram que $81,6 \%$ dos entrevistados consumiam álcool. Já Amorim et al. (2012), em estudo realizado em João Pessoa, com estudantes de Medicina, em 2010, evidenciaram que 76,8\% consumiam bebidas alcóolicas.

Barbosa et al. (2013), num estudo envolvendo estudantes de Medicina da Universidade Federal do Maranhão, em 2010, revelaram que $64,2 \%$ consumiam bebidas alcóolicas com frequência. No mesmo estudo foi identificado que o hábito de beber foi maior entre estudantes do sexo masculino $(58,7 \%)$. No estudo de Cavalcante et al. (2012), a prevalência do consumo de álcool entre estudantes de Farmácia da Universidade Federal do Maranhão, em 2011, foi de $80 \%$ no sexo feminino e de $96,8 \%$ no sexo masculino.

Rocha et al. (2011), num estudo com estudantes dos cursos de Medicina de duas faculdades em Minas Gerais, em 2009, demonstraram que $63,6 \%$ bebem álcool com frequência. Uma ou menos de uma vez por semana, $28 \%$; duas a quatro vezes por mês, $28,9 \%$; duas a três vezes por semana, $6,5 \%$; ou quatro ou mais vezes por semana, $0,2 \%$. O estudo realizado por Petroianu et al. (2010) demonstrou que $37,7 \%$ dos estudantes consomem álcool pelo menos uma vez por semana.

Ramis et al. (2012), numa pesquisa com estudantes que ingressaram na Universidade Federal de Pelotas, em 2008 , constataram que $74,5 \%$ dos estudantes do sexo masculino consomem álcool com frequência, sendo que o maior consumo se dá duas a quatro vezes por mês $(33,3 \%)$ e $75,3 \%$ dos estudantes entrevistados do sexo feminino consomem álcool com frequência, sendo que o maior consumo é mensalmente ou menos $(35,7 \%)$.

Andrade et al. (2012), em estudo que avaliou a prevalência do uso de drogas entre universitários brasileiros, revelaram que o álcool foi a droga mais consumida na população estudada. Além disso, os dados apontaram que os homens são mais propensos a usar álcool que as mulheres, e estudantes com idade entre 18 e 24 anos são os que mais consomem bebidas alcoólicas.

Concluiu-se, a partir da revisão integrativa, que há uma alta prevalência de consumo de bebidas alcoólicas entre universitários, evidenciando a necessidade de práticas de promoção à saúde dentro das universidades.

\section{Oficina de educação em saúde}

A oficina foi desenvolvida no espaço físico do Programa de Reorientação da Formação Profissional em Saúde (Pró-Saúde) de uma universidade do oeste catarinense. Para a operacionalização da prática foi utilizada a técnica de painel com questões norteadoras. De acordo com Anastasiou e Alves (2006), o painel é uma estratégia de discussão informal que pode ser utilizada para mobilização, construção ou elaboração de síntese de um conhecimento.

Participaram do presente estudo seis estudantes, que são nominados como petianos (termo utilizado no 
âmbito dos programas quando se refere aos estudantes que participam do PET), uma tutora e uma preceptora de grupos PET da universidade. Um estudante pertencia ao grupo PET-Vigilância em Saúde, outro ao grupo PETRedes de Atenção à Saúde e quatro acadêmicos, a tutora e a preceptora faziam parte do grupo PET-Promoção da Saúde. Também participaram dessa atividade duas mestrandas do Programa de Pós-Graduação em Ciências da Saúde (PPGCS) da mesma universidade. Os participantes tinham formação acadêmica em diversas áreas: Nutrição, Serviço Social, Psicologia, Medicina, Farmácia e Biologia. A escolha dos sujeitos foi intencional, com o propósito de compor um grupo multiprofissional. De acordo com Morais et al. (2012), a multidisciplinaridade tende a favorecer a apreensão de um novo conhecimento para a produção de outras práticas que intencionam a articulação do saber com as necessidades dos indivíduos.

Inicialmente, com o objetivo de problematizar o tema, foi apresentado o resultado da revisão integrativa sobre índices epidemiológicos. Na sequência, um vídeo que continha reportagem sobre o consumo de bebidas alcoólicas por jovens universitários. Segundo Carvalho e Ivanoff (2010), os vídeos são instrumentos que podem acelerar o processo de ensinar e aprender, uma vez que tratam de forma contextualizada as situações práticas e rotineiras. Estes são capazes de expressar aspectos culturais, espaciais e de linguagem, de forma variada e atraente, aproximando a temática ao contexto do educando.

\subsection{As vulnerabilidades no consumo de álcool entre universitários}

Após sensibilização sobre a problemática, foram trabalhados os conceitos de vulnerabilidade individual, social e programática. Sob a perspectiva de Ayres et al. (2003), a vulnerabilidade se constitui na exposição das pessoas ao adoecimento como resultado de aspectos não apenas individuais, mas também coletivos e contextuais. Os autores ressaltam que a vulnerabilidade individual:

Diz respeito ao grau e à qualidade da informação de que os indivíduos dispõem sobre o problema; à capacidade de elaborar essas informações e incorporálas aos seus repertórios cotidianos de preocupações; e, finalmente, ao interesse e às possibilidades efetivas de transformar essas preocupações em práticas protegidas e protetoras (AYRES et al., 2003, p. 123).

A vulnerabilidade social, segundo Ayres et al. (2003, p. 123):

Diz respeito à obtenção de informação, às possibilidades de metabolizá-las e ao poder de as incorporar a mudanças práticas, o que não depende só dos indivíduos, mas de aspectos, como acesso a meios de comunicação, escolarização, disponibilidade de recursos materiais, poder de influenciar decisões políticas, possibilidade de enfrentar barreiras culturais, estar livre de coerções violentas, ou poder defender-se delas etc.

Já a vulnerabilidade programática relaciona-se com os recursos sociais que os indivíduos necessitam para não se exporem a riscos de adoecimento ou para se protegerem dos danos que tais riscos podem causar. Para isso, é necessária a disponibilização de esforços programáticos, de modos efetivos e democráticos (AYRES, et al., 2003).

Após reflexão introdutória sobre o tema proposto, iniciou-se a técnica de Painel, com perguntas norteadoras. Ao total, quatro perguntas foram dirigidas aos participantes, que ficaram dispostos em círculo, refletindo e problematizando sobre o tema. Não foi estipulado tempo para debate, para que todos tivessem a oportunidade de expressar suas percepções com tranquilidade. Dessa forma, através das respostas, foi possível construir o painel com as opiniões dos participantes sobre os diferentes aspectos relacionados à vulnerabilidade de universitários perante o consumo de álcool.

A primeira pergunta norteadora relacionou-se com a vulnerabilidade individual: "Quais as consequências físicas provocadas pelo consumo de álcool entre universitários?". Essa questão provocou o grupo a refletir e a identificar os aspectos de vulnerabilidade individual, conforme demonstra a Figura 1.

\section{VULNERABILIDADES INDIVIDUAIS PROVOCADAS PELO} CONSUMO DE ÁLCOOL ENTRE UNIVERSITÁRIOS

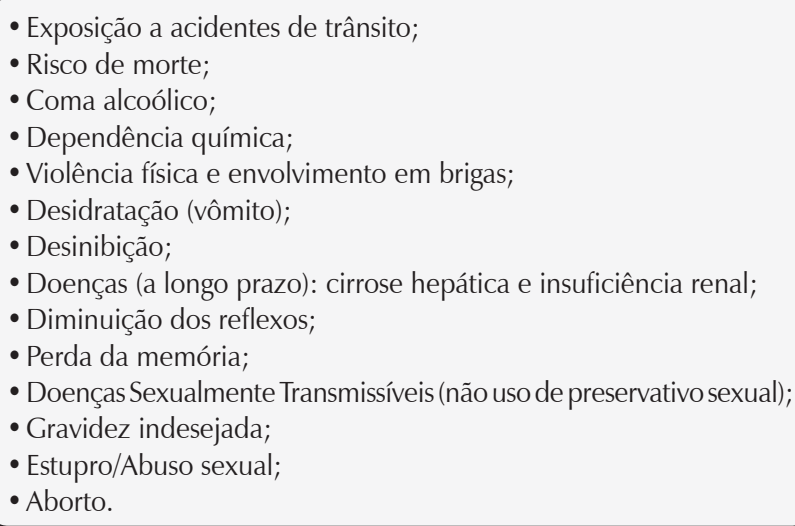

Figura 1. Painel sobre vulnerabilidades individuais de universitários perante o consumo de álcool. Construído pelo grupo PET-Saúde, Unochapecó, 2014

A Figura 1 revela que os petianos identificaram várias consequências físicas provocadas pelo consumo do álcool por universitários. E a exposição a acidentes de trânsito foi a primeira consequência referida. $\mathrm{O}$ grupo, durante 
o debate, ressaltou que estudantes alcoolizados podem provocar acidentes capazes de gerar ferimentos pessoais e em terceiros.

Foi apontada como fator de risco para condutas não habituais a desinibição provocada pelo consumo de bebidas alcoólicas. Os petianos referiram que estudantes alcoolizados podem tomar iniciativas que não tomariam se estivessem sóbrios. Além disso, afirmaram que jovens alcoolizados estão mais expostos ao abuso sexual e ao sexo desprotegido.

Os itens apontados pelos participantes da oficina são corroborados e complementados por estudo de Andrade et al. (2010), que concluiu que estudantes sob influência do álcool estão mais expostos a riscos de acidentes de trânsito, intoxicação, atos de violência e abuso sexual, sexo sem uso de preservativo, além de se mostrarem mais susceptíveis a problemas acadêmicos e de aprendizado e a comportamentos inadequados.

A exposição a doenças sexualmente transmissíveis (DSTs), gravidez indesejada e aborto pelo uso do álcool também foi ressaltada pelos petianos. Os participantes da oficina demostraram conhecimento em relação a esses aspectos. Estudo de Pedrosa et al. (2011), realizado no Nordeste, com 608 estudantes universitários da área da saúde, encontrou realidade diferente, pois os resultados indicaram que $60,7 \%$ dos entrevistados referiram não conhecer os efeitos do álcool. Resultado preocupante, visto que estes serão profissionais que têm entre suas competências conscientizar e sensibilizar a população para medidas preventivas.

O estudo de Pillon, O’Brien e Chavez (2005) também apontou comportamentos de risco relacionados à sexualidade e a acidentes de trânsito após o consumo de substâncias psicoativas. Neste, os autores afirmaram que estudantes do sexo masculino têm maior frequência de relações sexuais, com diferentes parceiros, sem uso de preservativos, quando estão sob o efeito do consumo de álcool. Revelaram que 23,5\% dos universitários dirigem após consumirem bebidas alcoólicas e, destes, 17\% se envolvem em acidentes de trânsito.

No painel, a violência física e o envolvimento em brigas foram apontados pelos participantes como um problema de vulnerabilidade individual. O estudo de Pillon, O'Brien e Chavez evidenciou que a violência está presente entre usuários de drogas ilícitas e consumidores de álcool. Entre universitários, o comportamento agressivo não é identificado somente entre os dependentes, também pode ser encontrado em consumidores ocasionais de bebidas alcoólicas. Segundo os autores, $16,5 \%$ dos estudantes já brigaram por estarem sob efeito de alguma substância psicoativa e $21 \%$ já ameaçaram pessoas com armas de fogo.

A segunda pergunta norteadora realizada na oficina relacionava-se com a vulnerabilidade social e tinha como objetivo problematizar sobre: "Quais as consequências sociais provocadas pelo uso do álcool entre universitários?". O painel foi construído com as respostas demonstradas na Figura 2.

\section{VULNERABILIDADES SOCIAIS PROVOCADAS PELO CONSUMO DE ÁLCOOL ENTRE UNIVERSITÁRIOS}

- Perda de emprego;

- Perda da credibilidade profissional e universitária;

- Desestruturação familiar;

- Congestionamento do trânsito (por causa de acidentes automobilísticos).

Figura 2. Painel sobre vulnerabilidades sociais perante o consumo de álcool entre universitários. Construído pelo grupo PET-Saúde, Unochapecó, 2014

Conforme apontado na Figura 2, o grupo referiu a perda do emprego e da credibilidade profissional e universitária, além da desestruturação familiar como principais aspectos de vulnerabilidade social perante o consumo de álcool entre universitários. Alguns participantes relataram que conhecem casos de colegas que perderam emprego e que são "malvistos" por consumirem bebidas alcoólicas em momentos inoportunos e/ou em quantidade exagerada.

A desestruturação da família, apontada durante o debate do painel, pode se constituir em um fator de risco para a indução à dependência química. De acordo com Hermeto, Sampaio e Carneiro (2010), um ambiente familiar dominado por conflitos ou pela falta de estabelecimento de regras apresenta-se como potencial indutor a condutas inadequadas com relação ao consumo de álcool por adolescentes.

Chama a atenção o fato de o grupo descrever como vulnerabilidade social o congestionamento de trânsito causado por acidente automobilístico envolvendo estudantes alcoolizados. Notou-se, durante o debate do painel, que o grupo considera como irresponsabilidade um ato pessoal trazer prejuízos sociais.

Wagner e Andrade (2008) revelaram alguns comportamentos de risco entre a classe universitária após consumo de bebida alcoólica, dentre eles: violência, relações sexuais sem proteção e direção perigosa. Os petianos também apontaram tais comportamentos como consequências do consumo de álcool.

Paulino e Lopes (2010) destacaram em seu estudo que as habilidades intelectuais ajudam os jovens a perceber melhor os riscos dessa natureza. Para tanto, o bom funcionamento destas pode auxiliar na compreensão das consequências de seus atos, ajudando-os a evitar situações de vulnerabilidade social. Cabe destacar que a educação em saúde pode se constituir numa estratégia de enfrentamento dessa problemática. 
A terceira pergunta relacionou-se com a vulnerabilidade programática: "Quais políticas de prevenção ao uso de álcool entre universitários vocês conhecem?". O conhecimento dos participantes do PET-Saúde sobre essa questão está apresentado na Figura 3.

\section{POLÍTICAS DE PREVENÇÃO AO CONSUMO DE ÁLCOOL} ENTRE UNIVERSITÁRIOS CONHECIDAS PELO GRUPO

- Proibição de venda de álcool dentro da universidade;

- Políticas de conscientização contra o uso abusivo de álcool;

- Lei seca;

- Campanhas do Corpo de Bombeiros.

Figura 3. Painel construído por estudantes e tutor de grupos PET-Saúde, a partir de pergunta norteadora relacionada com a vulnerabilidade programática perante o uso de álcool entre universitários. Oeste de Santa Catarina, 2014

Dentre os apontamentos para a questão da vulnerabilidade programática, os petianos referiram a proibição da venda de álcool dentro da universidade. Uma política institucional da universidade proíbe a comercialização de qualquer tipo de bebida alcoólica dentro do campus universitário. Entretanto, os universitários referiram que o controle do consumo no interior da instituição é difícil, uma vez que vários estudantes compram bebidas alcoólicas nos comércios próximos e consomem de forma "disfarçada" no interior da mesma.

Cabe ressaltar que, apesar de o álcool ser uma droga legalizada e culturalmente aceita em nossa sociedade, há restrições legais quanto à sua venda e consumo. No Estado de Santa Catarina, por exemplo, existe a Lei no 12.948 , de 11 de maio de 2004, que pró́be a venda e o consumo de bebidas alcoólicas no ambiente físico das escolas públicas e privadas, nos estabelecimentos de ensino dos cursos fundamental, médio, superior, técnico e profissionalizante (BRASIL, 2004).

Segundo os petianos, as políticas de conscientização contra o uso abusivo de álcool, veiculadas principalmente na televisão e no rádio, são estratégias eficientes no combate às vulnerabilidades diante do consumo dessas bebidas, porém sua linguagem nem sempre é adequada ao público jovem. De acordo com Stamm e Bressan (2007), há falta de uma política adequada de controle da propaganda, que geralmente associa o consumo de bebida alcoólica aos bons momentos da vida. Igualmente, a facilidade de obter o produto, tanto pela disponibilidade quanto pela variedade e baixo preço, tornam o álcool uma droga atrativa, acessível e presente no universo juvenil. Além disso, os autores apontam que tanto as famílias como a sociedade aceitam com certa naturalidade um jovem consumir bebidas alcoólicas.
Os participantes do estudo referiram a Lei $\mathrm{n}$ - 11.705 , de 2008, conhecida por "Lei Seca", como uma estratégia política para controlar o consumo de álcool na população em geral e entre os universitários (BRASIL, 2008a). Para eles, a lei parece ter favorecido a redução do consumo de álcool, principalmente entre os jovens que irão dirigir após uma comemoração ou festa.

Outra ação citada como preventiva foram as campanhas do Corpo de Bombeiros. Os participantes referiram que a corporação tem papel relevante na conscientização de jovens sobre os perigos do consumo de substâncias psicoativas. Entretanto, citaram que tais campanhas poderiam ser realizadas de maneira mais frequente e dentro da universidade, envolvendo todos os cursos.

\subsection{Proposta de enfrentamento das vulnerabilidades}

Após os debates em relação às vulnerabilidades individual, social e programática, foi encaminhada a atividade de elaboração de painel (Figura 4) com medidas que, na opinião dos petianos, podem ser tomadas para prevenir ou reduzir a exposição ao consumo de álcool entre os universitários.

MEDIDAS PARA MINIMIZAR AS VULNERABILIDADES DO CONSUMO DE ÁLCOOL ENTRE UNIVERSITÁRIOS

- Campanhas com uso de imagens e vídeos dentro das universidades;

- Capacitação de jovens para desenvolver campanhas de jovem para jovem;

- Programas para conscientização de crianças e adolescentes para prevenir o consumo precoce de bebidas alcoólicas;

- Criação de mais oportunidade de ocupação para os jovens;

- Conscientização dos pais e/ou responsáveis;

- Campanhas de incentivo ao consumo de bebidas sem álcool;

- Trabalho multiprofissional.

Figura 4. Painel com propostas para minimizar as vulnerabilidades provocadas pelo consumo do álcool entre os universitários. Construído pelo grupo PET-Saúde, Unochapecó, 2014

A atividade foi baseada na estratégia "solução de problemas" proposta por Anastasiou e Alves (2006), que busca a construção de diferentes alternativas para a resolução dessa questão.

O uso de imagens e vídeos impactantes, relacionados aos danos que o consumo de álcool pode causar, foi apontado como uma medida de conscientização. Os petianos consideram que cenas chocantes alertam os consumidores e citaram como exemplo disso as imagens utilizadas nas embalagens de cigarro.

Foi referida também a importância da educação por pares "de jovens para jovens". O grupo explica que quando os jovens estão envolvidos na criação de mecanismos que 
buscam evitar os danos causados pelo consumo excessivo de drogas, sejam elas lícitas ou ilícitas, geram maior resultado final. Esse envolvimento torna a linguagem utilizada nas campanhas e nos meios de divulgação mais apropriada. O grupo também ressaltou a importância de realizar atividades preventivas com crianças, adolescentes, pais e/ou responsáveis, com o objetivo de mitigar situações de exposição a vulnerabilidades quando os mesmos tornarem-se universitários.

Cabe ressaltar que a educação entre pares vem sendo utilizada e apresenta resultados positivos, pois, além de garantir a participação do jovem na condução de todo o trabalho, promove o desenvolvimento de seus conhecimentos, atitudes e habilidades. Ao assumir essa responsabilidade, eles colocam cada vez mais o seu jeito de ser e passam a utilizar ferramentas próprias da sua vivência (PENIDO et al., 2008).

Uma proposta curiosa que surgiu no grupo foi a de promover o incentivo da substituição do consumo de bebidas alcoólicas por bebidas do mesmo tipo, mas sem álcool. De acordo com o grupo, esse costume se configuraria como um efeito placebo e poderia proteger os jovens da exposição às vulnerabilidades.

Outrossim, o grupo considerou que nenhum profissional da área de saúde conseguiria prevenir sozinho a exposição às vulnerabilidades causada pelo consumo de álcool entre universitários. Ficando evidente a importância do trabalho multiprofissional para tentar resolver situações complexas que envolvem diversos aspectos de suscetibilidade em saúde.

Além da abordagem multidisciplinar de prevenção ao consumo de álcool, é necessário o trabalho intersetorial entre a saúde e a educação. Sobre esse aspecto, mencionase que a educação em saúde deve ser uma ação baseada na troca de saberes vinculada ao dia a dia das pessoas envolvidas numa problemática, ultrapassando a visão tecnicista e biologicista das doenças e envolvendo também os processos culturais que permeiam os agravos à saúde (VASCONCELOS, 2006). Sendo assim "a valorização do saber e valores do educando permitem que ele se sinta 'em casa' e mantenha sua iniciativa. Neste sentido, não se reproduz a passividade usual dos processos pedagógicos tradicionais" (VASCONCELOS, 2004, p. 71).

Vale destacar que as práticas de educação em saúde abarcam três segmentos - os profissionais de saúde, os gestores e a população - que ampliam seus conhecimentos e sua autonomia nos cuidados à saúde (FALKENBERG et al., 2014). Portanto, "a educação em saúde como processo político pedagógico requer o desenvolvimento de um pensar crítico e reflexivo, permitindo desvelar a realidade e propor ações transformadoras", bem como sugerir a emancipação na tomada de decisões individuais e coletivas (MACHADO et al., 2007).

\section{CONSIDERAÇõES FINAIS}

$\mathrm{Na}$ revisão integrativa, evidenciou-se a alta prevalência do consumo de álcool entre universitários, apontando a necessidade de debater e alvitrar medidas de proteção sobre essa problemática nos espaços universitários.

Por meio de uma metodologia ativa com os atores PET-Saúde, a intervenção educativa resultou no (re)conhecimento das vulnerabilidades dos universitários perante o consumo de bebidas alcoólicas, além da elaboração de propostas concretas, factíveis de execução, para o enfrentamento dessa situação. A mobilização de atores dos diversos grupos do Pet da universidade teve por objetivo instigar que os estudantes assumissem o papel de multiplicadores desse conhecimento em seus grupos. Essa estratégia ampliou o número de sujeitos envolvidos na prática de educação em saúde e desenvolveu habilidades profissionais nos estudantes para o exercício desse trabalho em rede.

Por fim, ressalta-se a importância do desenvolvimento de metodologias ativas nos programas do PETSaúde. Pois as práticas de educação que estimulam a problematização e a busca de superação das dificuldades vêm ao encontro da proposta governamental. E esta visa a formar um profissional de saúde capaz de compreender a dinâmica do processo saúde e adoecimento e de atuar de forma multiprofissional, interdisciplinar e intersetorial.

\section{REFERÊNCIAS}

AMORIM, Thiago Chaves et al. Avaliação da dependência alcoólica entre estudantes de medicina no nordeste brasileiro pelo teste de identificação de distúrbio de uso do álcool e a relação com o índice de massa corpórea e tabagismo. Rev. Soc. Bras. Clín. Méd., v. 10, n. 5, p. 398-401.

ANASTASIOU, Léa das Graças Camargo; ALVES, Leonir Pessate. Processos de ensinagem na universidade: pressupostos para as estratégias de trabalho em aula. 6 . ed. Joinvile: Univille, 2006.

ANDRADE, Arthur Guerra de et al. Use of alcohol and other drugs among Brazilian college students: effects of gender and age. Rev. Bras. Psiq., v. 34, n. 3, p. 294-305, 2012.

ANDRADE, Laura Helena Silveira Guerra de et al. Padrões de consumo de álcool entre universitários. In: BRASIL. Ministério da Saúde. Secretaria Nacional de Políticas sobre Drogas. I Levantamento Nacional sobre o Uso de Álcool, Tabaco e Outras Drogas entre Universitários das 27 Capitais Brasileiras. Brasília: Ministério da Saúde, 2010, 284 p.

AYRES, José Ricardo de Carvalho Mesquita et al. O conceito de vulnerabilidade e as práticas de saúde: novas perspectivas e desafios. In: CZERESNIA, Dina; FREITAS, Carlos Machado de. Promoção da saúde: conceitos, reflexões, tendências. Rio de Janeiro: Fiocruz, 2003. 
BARBOSA, Felipe Lacerda et al. Uso de álcool entre estudantes de Medicina da Universidade Federal do Maranhão. Rev. Bras. Educ. Méd., v. 37, n. 1, p. 89-95, 2013.

BRASIL. Lei no 12.948, de 11 de maio de 2004. Proíbe a venda e o consumo de bebidas alcoólicas no ambiente físico das escolas públicas e privadas, nos estabelecimentos de ensino dos cursos fundamental, médio, superior, técnico e profissionalizante do Estado de Santa Catarina. Diário Oficial da União, 11 de maio de 2004.

. Lei no 11.705 , de 19 de junho de 2008. Altera a Lei n⿳⺈ 9.503, de 23 de setembro de 1997, que 'institui o Código de Trânsito Brasileiro', e a Lei no 9.294, de 15 de julho de 1996, que dispõe sobre as restrições ao uso e à propaganda de produtos fumígeros, bebidas alcoólicas, medicamentos, terapias e defensivos agrícolas, nos termos do $\S 4$ o do art. 220 da Constituição Federal, para inibir o consumo de bebida alcoólica por condutor de veículo automotor, e dá outras providências. Brasília: Presidência da República, 2008a. Disponível em: <http://www.planalto.gov.br/ccivil 03/ ato2007-2010/2008/ lei/111705.htm>. Acesso em: 26 jun. $201 \overline{4}$.

Portaria Interministerial n. 1.802, de 26 de agosto de 2008. Institui o Programa de Educação pelo Trabalho para a Saúde - PET-Saúde. Diário Oficial da União. Brasília, 26 ago, $2008 b$.

. Ministério da Saúde. Secretaria Nacional de Políticas sobre Drogas. I Levantamento Nacional sobre o Uso de Álcool, Tabaco e Outras Drogas entre Universitários das 27 Capitais Brasileiras. Brasília: Senad, 2010.

. Ministério da Educação. Censo da Educação Superior 2012. Disponível em: < http://portal.inep.gov.br/web/censo-daeducacao-superior $\gg$. Acesso em: 24 abr. 2014.

CARVALHO, Fábio Câmara Araújo de; IVANOFF, Gregório Bittar. Tecnologias que educam: ensinar e aprender com as novas tecnologias de informação e comunicação. São Paulo: Pearson, 2010.

CAVALCANTE, Danielle Borges et al. Uso de álcool entre acadêmicos de farmácia de uma universidade pública. Rev. Bras. Enferm., v. 20, n. 3, p. 312-316, 2012.

CRUZ, Kathleen Tereza da et al. PET-Saúde: micropolítica, formação e o trabalho em saúde. Interface (Botucatu), Botucatu, v. 19, supl. 1, p. 721-730, 2015.

FALKENBERG, Mirian Benites et al. Educação em saúde e educação na saúde: conceitos e implicações para a saúde coletiva. Ciênc. Saúde Coletiva, Rio de Janeiro , v. 19, n. 3, p. 847-852, mar. 2014.

FERRAZ, Lucimare. O PET-Saúde e sua interlocução com o Pró-Saúde a partir da pesquisa: o relato dessa experiência. Rev. Bras. Educ. Méd., Rio de Janeiro, v. 36, n. 1, supl. 1, p. 166-171, mar., 2012.

GANONG, Lawrence H. Integrative reviews of nursing. Res. Nurs Health, v. 10, n. 1, p. 1-11, 1987.<https:/doi.org/10.1002/ nur.4770100103>

HERMETO, Edyr Marcelo Costa; SAMPAIO, José Jackson Coelho; CARNEIRO, Cleide. Abandono do uso de drogas ilícitas por adolescente: importância do suporte familiar. Rev. Baiana de Saúde Pública, v. 34, n. 3, p. 639-652, 2010.
MACHADO, Maria de Fátima Antero Sousa et al. Integralidade, formação de saúde, educação em saúde e as propostas do SUS: uma revisão conceitual. Ciênc. Saúde Coletiva, Rio de Janeiro, v. 12, n. 2, p. 335-342, abr. 2007.

MORIAS, Fátima Raquel Rosado et al. A importância do PETSaúde para a formação acadêmica do enfermeiro. Trab. Educ. Saúde, v. 10, n. 3, p. 541-551, 2012.

PAULINO, Janaina Aparecida; LOPES, Renata Ferrarez Fernandes. Relação entre percepção e comportamento de risco e níveis de habilidades cognitivas em um grupo de adolescentes em situação de vulnerabilidade social. Psicol. Ciênc. Prof., v. 30, n. 4, p. 752-765, 2010.

PEDROSA, Adriano Antonio da Silva et al. Consumo de álcool entre estudantes universitários. Cad. Saúde Pública, v. 27, n. 8, p. 1611-1621, 2011.

PENIDO, Anna et al. De jovem para jovem: educação entre pares. Unicef, 2008. Disponível em: <http://www.unicef.org/brazil/ pt/br_educacao_pares_vira.pdf>. Acesso em: 26 jun. 2014. PETROIANU, Andy et al. Prevalência do consumo de álcool, tabaco e entorpecentes por estudantes de Medicina da Universidade Federal de Minas Gerais. Rev. Assoc. Méd. Bras., v. 56, n. 5, p. 568-571, 2010.

PILLON, Sandra Cristina; O’BRIEN, Beverley; CHAVEZ, Ketty Aracely Piedra. The relationship between drug use and risk behaviors in Brazilian university students. Rev. Lat. Am. Enfermagem, v. 13, n. 2, p. 1169-1176, 2005.

RAMIS, Thiago Rozales et al. Tabagismo e consumo de álcool em estudantes universitários: prevalência e fatores associados. Rev. Bras. Epidem., v. 15, n. 2, p. 376-385, 2012.

ROCHA, Leandro Augusto et al. Consumo de álcool entre estudantes de faculdades de Medicina de Minas Gerais, Brasil. Rev. Bras. Educ Méd., v. 35, n. 3, p. 369-375, 2011.

SORDI, Mara Regina Lemes De et al. O potencial da avaliação formativa nos processos de mudança da formação dos profissionais da saúde. Interface (Botucatu), Botucatu, v. 19, supl. 1, p. 731-742, 2015.

STAMM, Mariestela; BRESSAN, Liamari. Consumo de álcool entre estudantes do curso de Enfermagem de um município do oeste catarinense. Ciênc. Cuid. Saúde, v. 6, n. 3, p. 319-324, 2007.

VASCONCELOS, Eymard Mourão. Educação popular: de uma prática alternativa a uma estratégia de gestão participativa das políticas de saúde. Physis, Rio de Janeiro, v. 14, n. 1, p. 67-83, jun. 2004.

VASCONCELOS, E. M. Educação popular e a atenção à saúde da família. 3. ed. São Paulo: Hucitec, 2006.

VIEIRA, Valéria Cristina Ribeiro et al. Perfil socioeconômico, nutricional e de saúde de adolescentes recém-ingressos em uma universidade pública brasileira. Rev. Nutr., v, 15, n. 3, p. 273-282, 2002.

WAGNER, Gabriela Arantes; ANDRADE, Arthur Guerra de. Uso de álcool, tabaco e outras drogas entre estudantes universitários brasileiros. Rev. Psiq. Clín., v. 35, n. 1, p. 48-54.

Submetido em 12/03/2015

Aprovado em 04/02/2016 